( $90 \%$ of the US population) and the other, slow or poor metabolizers (10\% of population). CYP 2D6 genotype was determined at study entry to determine which patients should receive smaller doses and those who may require higher amounts. The final dose in poor metabolizers was one third that used in extensive metabolizers $(0.5 \mathrm{mg} / \mathrm{kg} / \mathrm{d}$ versus $1.5 \mathrm{mg} / \mathrm{kg} / \mathrm{d})$. Although the safety and tolerability of these doses appeared to be similar in the 2 groups, further studies will be needed to define safety in the poor metabolizers. Should determination of the genotype for slow metabolizers be necessary before starting treatment, this would seriously detract from the use of atomoxetine in practice.

\title{
CHROMOSOMAL ABNORMALITIES IN ADHD
}

The prevalence of fragile $X$ syndrome, velocardiofacial syndrome (VCFS), and other cytogenetic abnormalities among 100 children ( 64 boys) with combined type $\mathrm{ADHD}$ and normal intelligence was assessed at the $\mathrm{NIMH}$ and Georgetown University Medical Center. One girl with ADHD had a sex chromosome aneuploidy $(47, \mathrm{XXX}) ; 1$ boy had a premutation-sized allele for fragile $\mathrm{X}$ and none showed the full mutation. Testing for 22q11.2 microdeletion characteristic of VCFS was negative for all subjects screened. The results were not different from those expected by chance. Prevalences exceeding $5.5 \%$ for chromosomal abnormalities, $3.7 \%$ for VCFS, and $3.6 \%$ for fragile X full mutations were excluded. In children with $\mathrm{ADHD}$ and normal intelligence with no clinical signs and absent family history of chromosome anomalies, testing for cytogenetic abnormalities is not warranted. (Bastain TM, Lewczyk CM, Sharp WS et al. Cytogenetic abnormalities in attention-deficit/hyperactivity disorder. L Am Acad Child Adolesc Psychiatry July 2002;41:806-810). (Reprints: Dr F Xavier Castellanos, NYU Child Study Center, 577 First Ave, New York, NY 10016).

COMMENT. In the absence of clinical indications, including developmental delay, physical signs, or positive family history, testing for chromosomal abnormalities, VCFS, or fragile $\mathrm{X}$ is not indicated in children with ADHD of normal intelligence.

Cigarette smoking in adolescents with ADHD. Cigarette smoking was associated with family and peer smoking and with clinically significant ADHD inattention symptoms in a confidential self-report survey of 1066 tenth-grade students in five public high schools conducted at the Lombardi Cancer Center, Washington, DC. ADHD inattentive type is a significant risk factor for cigarette smoking in adolescents. (Tercyak KP et al. LAm Acad Child Adolesc Psychiatry July 2002;41:799-805).

Altered cortical activity in ADHD during attentional load task is demonstrated by quantitative electroencephalography performed with eyes open and during Continuous Performance Task. Increased slow activity over frontal areas and decreased fast cortical activity were observed, indicating a different arousal pattern and possible delay in cortical maturation. (El-Sayed E, et al. L Am Acad Child Adolesc Psychiatry July 2002;41:811-819).

\section{LEARNING DISABILITIES}

\section{PATTERN OF LEARNING DISABILITIES IN ELBW CHILDREN}

The prevalence and pattern of specific learning disabilities (LD) in neurologically normal children with extremely low birth weight (ELBW) $(<800 \mathrm{~g})$ 